\title{
3 Research Square

\section{Development of a low-cost outdoor carbon monoxide analyzer applied to the city of Oran, Algeria.}

Farid RAHAL ( $\nabla$ farid.rahal.dz@gmail.com )

Université des Sciences et de la Technologie d'Oran Mohamed Boudiaf https://orcid.org/0000-00017495-8324

Noureddine BENABADJI

Universite des Sciences et de la Technologie d'Oran Mohamed Boudiaf

Mohamed BENCHERIF

Universite des Sciences et de la Technologie d'Oran Mohamed Boudiaf

Mohamed Menaouer BENCHERIF

Universite des Sciences et de la Technologie d'Oran Mohamed Boudiaf

\section{Research}

Keywords: Air quality, carbon monoxide, electrochemical sensor, microcontroller, APOMOS

Posted Date: July 10th, 2020

DOI: https://doi.org/10.21203/rs.3.rs-38652/v1

License: (c) (i) This work is licensed under a Creative Commons Attribution 4.0 International License. Read Full License 
1 Development of a low-cost outdoor carbon monoxide analyzer applied to the city of Oran, Algeria.

3 Farid Rahal ${ }^{* 1}$, Noureddine BENABADJI ${ }^{2}$, Mohamed BENCHERIF ${ }^{3}$ and Mohamed Menaouer BENCHERIF ${ }^{4}$ University of science and technology of Oran Mohamed Boudiaf BP 1505 El M'naouer - Oran, Algeria University of science and technology of Oran Mohamed Boudiaf 
In Algeria, air pollution is classified as a major risk by the law. However, this risk is

21 underestimated because there is no operational network for measuring air quality on a continuous basis.

23 Despite the heavy investments made to equip several cities with these measurement

24 systems, they are out of order due to a lack of continuous financial support.

25 The alternative to the absence of these air pollution measurement networks can come

26 from the recent development of electrochemical sensor technologies for air quality

27 monitoring which arouses a certain interest because of their miniaturization, low

28 energy consumption and low cost.

29 We developed a low-cost outdoor carbon monoxide analyzer called APOMOS (Air

30 pollution Monitoring System) based on electrochemical sensor managed by

31 microcontroller. An application developed with the Python language makes it possible

32 to manage process and analyze the collected data.

33 In order to validate the APOMOS system, the recorded measurements are compared

34 with measurements taken by a conventional analyzer.

35 Comparison of the measurements resulting from conventional analyzer and those 
resulting from the APOMOS system gives a coefficient of determination of $98.39 \%$.

Two versions of this system have been designed. A fixed version and another

embedded, equipped with a GPS sensor. These 2 variants were used in the city of

Oran in Algeria to measure the concentration of carbon monoxide continuously.

41 system allows its evolution in an easy way in order to integrate other sensors

42 concerning the various atmospheric pollutants.

43 Keywords: Air quality, carbon monoxide, electrochemical sensor, microcontroller,

44 APOMOS.

\section{Introduction}

Algeria has environmental problems, especially in highly industrialized and fastgrowing urban areas such as Algiers, Oran and Annaba [1].

Indeed, the intense development of urbanization has largely contributed to the degradation of ambient air quality [2]. However, there is currently no network for the continuous measurement of air quality or data on levels of air pollution in large urban centers. 
53 located in the north-west of the country as shown by Figure 1, spread out according to

54 a rapid pace of urban growth by artificialising an average of 110 ha per year [3]. It

55 postponed its urbanization on neighboring agglomerations [4]. In recent years, these

56 have become urban suburbs, encompassed by the dynamics of the agglomeration. This

57 resulted in the creation of a metropolis of more than one million inhabitants since 2008,

58 bringing together six chief towns of communes (Oran, Es Senia, Bir El Djir, Sidi Chami,

59 El Kerma et Hassi Bounif) [5].

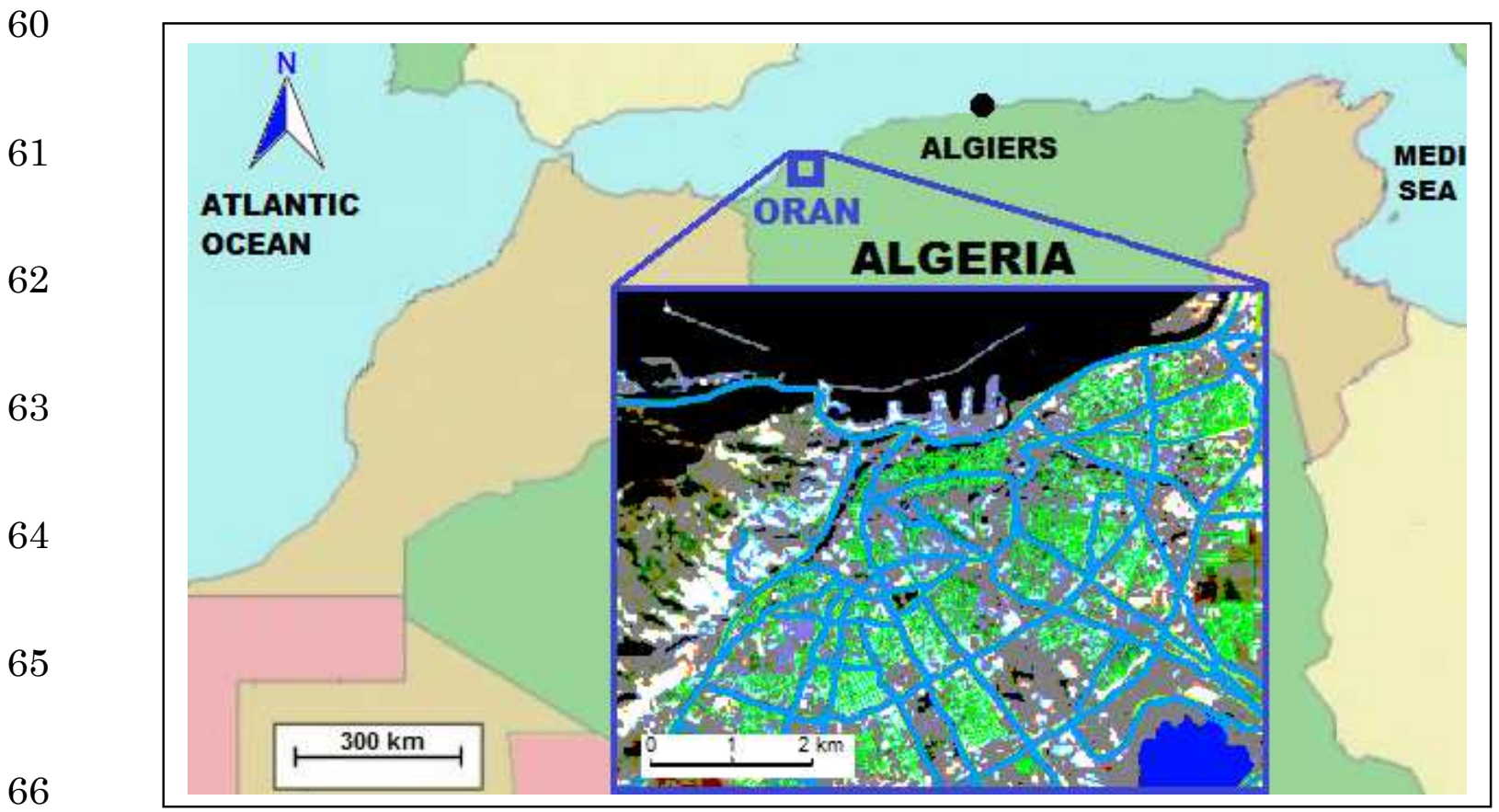

$67 \quad$ Fig.1 Geographic position of Oran city in Algeria.

$68 \quad$ Source : Authors. 
71 and a sharp increase in the population of the neighboring communes of Bir el Djir, Sidi

72 Chahmi and Es Senia [6]. This phenomenon accentuates the need for mobility to the

73 center of Oran because of its high attractiveness due to employment, shopping and

74 leisure generating traffic overloads, thus contributing to the deterioration of air quality.

75 In order to assess the state of atmospheric pollution in the Oran region, it is

76 necessary to measure it. The use of a system based on low-cost electrochemical sensors

77 can be an interesting alternative in the absence of a network for the continuous

78 measurement of air pollution.

79 In recent years, there has been a sharp rise in the use of low-cost sensor technologies

80 for air pollution monitoring efforts [7,8].

81 These sensors are generally small, consume little energy, cost between 10 and 1,000

82 US Dollars, and measure concentrations of all major air pollutants. Compared to large,

83 high-end solutions costing more than 100,000 US Dollars, low-cost sensors are

84 particularly useful for large-scale static and mobile deployments $[9,10,11]$.

85 Furthermore, low-cost air pollution sensors have been successfully integrated into

86 various long-term deployments to provide detailed information on air pollution for 
quantitative studies and utilities [12].

The goal of this work is to design an integrated and scalable low-cost system to

89 assess the continuous air quality in the Oran region. This system measures the

90 concentrations of carbon monoxide in the first step. It may, thereafter, incorporate

91 other electrochemical sensors for the main pollutants.

92

\section{Materials and methods}

94 Carbon monoxide, targeted in this study, is a major pollutant of air quality. It is an

95 important compound for tropospheric chemistry. It is the dominant sink for hydroxyl

96 radicals and is involved in ozone chemistry [13].

97 Carbon monoxide (CO) is a colorless and odorless gas that is very toxic. Liu et al.

98 [14] have provided, through a national survey of 272 Chinese cities, evidence of a

99 link between short-term exposure to carbon monoxide in ambient air and increased

100 mortality from cardiovascular disease.

$101 \mathrm{CO}$ is not only a pollutant, but its presence is also evidence of incomplete

102 combustion, resulting a loss of efficiency and therefore higher fuel consumption [15].

$103 \mathrm{CO}$ is formed during the combustion of biomass, fossil fuels and the oxidation of $\mathrm{CH} 4$ 
104 by $\mathrm{OH}$ radicals or other carbonaceous gases [16].

105 The high population density in the city of Oran causes heavy traffic [6]. The CO

106 emitted by the large number of mobile vehicles over a long period is detrimental to

107 human health [17].

108 In order to measure the concentrations of $\mathrm{CO}$ in outdoor ambient air in the Oran

109 region, the solid-state, high sensitivity CO - TGS 2442 sensor was used.

110 This solid-state gas sensor is the heart of the designed monitoring system. The

111 operating principle of the TGS2442 sensor is based on the sensitivity of certain metal

112 oxides to different gases. For TGS2442, tin dioxide ( $\mathrm{SnO} 2)$ reacts with CO molecules

113 in the presence of oxygen $(\mathrm{O} 2)$ and releases free electrons. The electrons increase the

114 conductivity and determine the decrease of the internal resistance. The sensor includes

115 a heating element that accelerates the chemical reaction and maintains an adequate

116 temperature inside the enclosure [15].

117 For each second, circuit voltage and heating voltage cycles are alternated as shown

118 in Figure 2.

119

120 


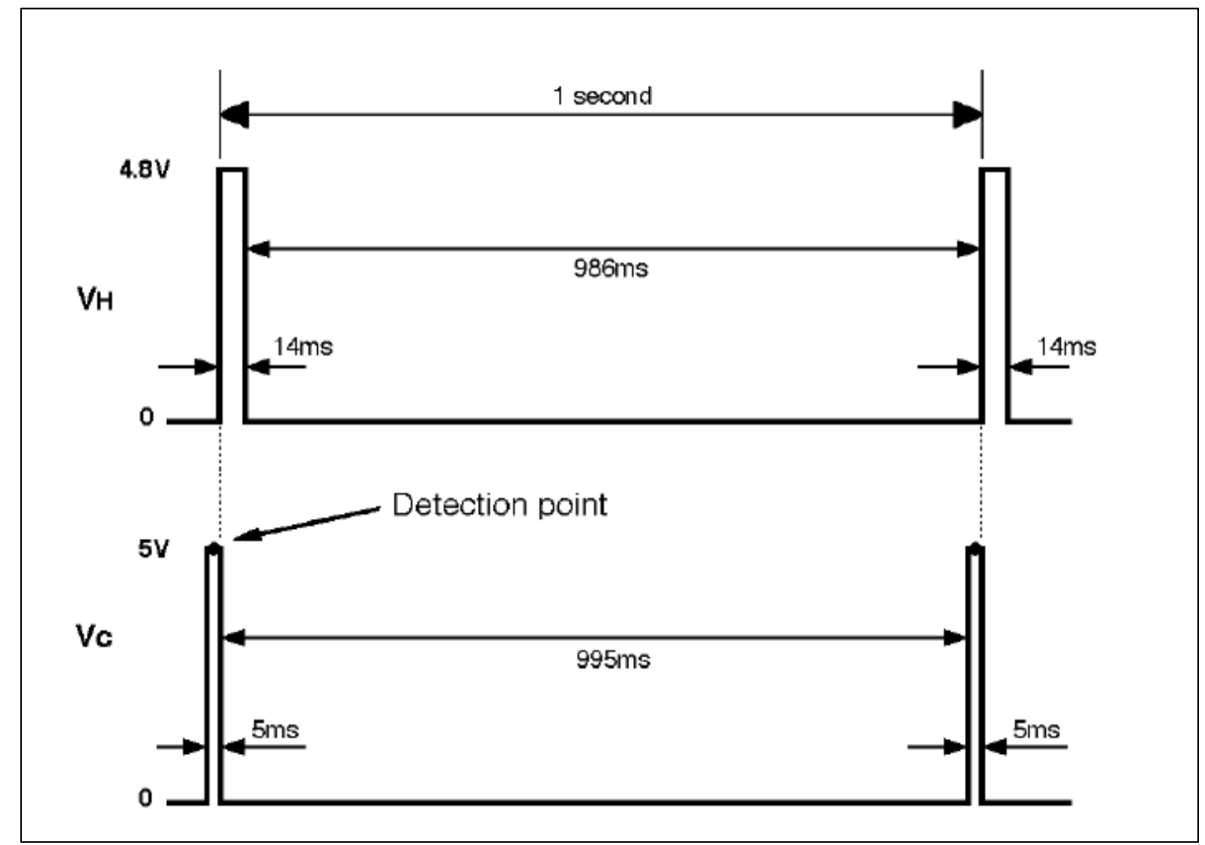

128 Fig.2 Circuit voltage and heating voltage cycles of TGS2442 Sensor. millisecond pulse starts immediately after the 5-millisecond pulse.

134

135

136 


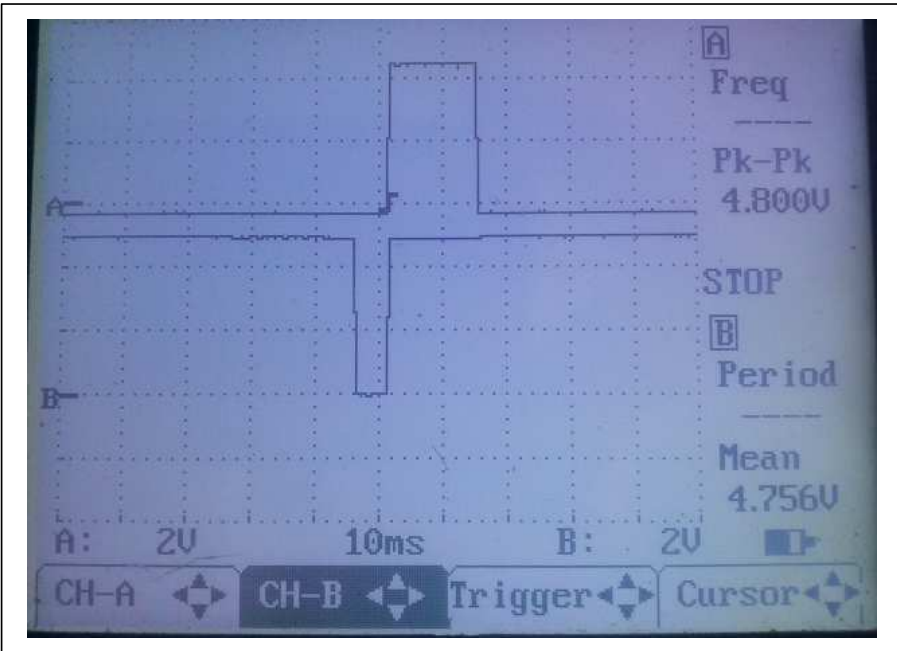

$143 \quad$ Fig.3 Double trace view of the outputs after 5 millisecond pulses followed by 14

144 millisecond pulses recorded by an oscilloscope.

$145 \quad$ Source : Authors

148 Monitoring System). It is equipped with a temperature sensor and a humidity sensor. transistor type ZTX651, itself controlled by the RC5 output of the microcontroller. 
155

156

157

158

159

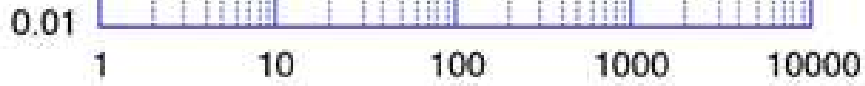

$160 \quad$ Fig.4 TGS2442 sensor response curves.

$161 \quad$ Source : [18]

162

163 According to the sensor manufacturer datasheet, the $\mathrm{CO}$ concentration is

164 determined according to the following formula (Figaro, 2001).

165

166

$\mathrm{C}=100 \times \mathrm{f}(\mathrm{Rs}) 1 / \alpha$

167

$168 \quad \mathrm{C}:$ Concentration in ppm

$169 \mathrm{f}(\mathrm{Rs})$ : Function of the sensor resistance

$170 \alpha:$ Slope of the sensitivity curve

171 

measurements for $50 \mathrm{ppm}$ and $150 \mathrm{ppm}$.

174

$$
\alpha=\frac{\log f(\mathrm{Rs})(150 \mathrm{ppm})-\log f(\mathrm{Rs})(50 \mathrm{ppm})}{\log 150-\log 50}
$$

175 MCP9700A, sensitive from $-40^{\circ} \mathrm{C}$ to $+125^{\circ} \mathrm{C}$, with an accuracy of $0.5 \%$, and a

178 quiescent current of $6 \mu \mathrm{A}$; It is also equipped with a humidity sensor type HCZ-J3A.

179 The information collected by these 2 sensors is necessary to calculate the 180 concentration of carbon monoxide because the measurements acquired on the TGS2442

181 are dependent on temperature and humidity as shown in Figure 5.

182

183

184

185

186 


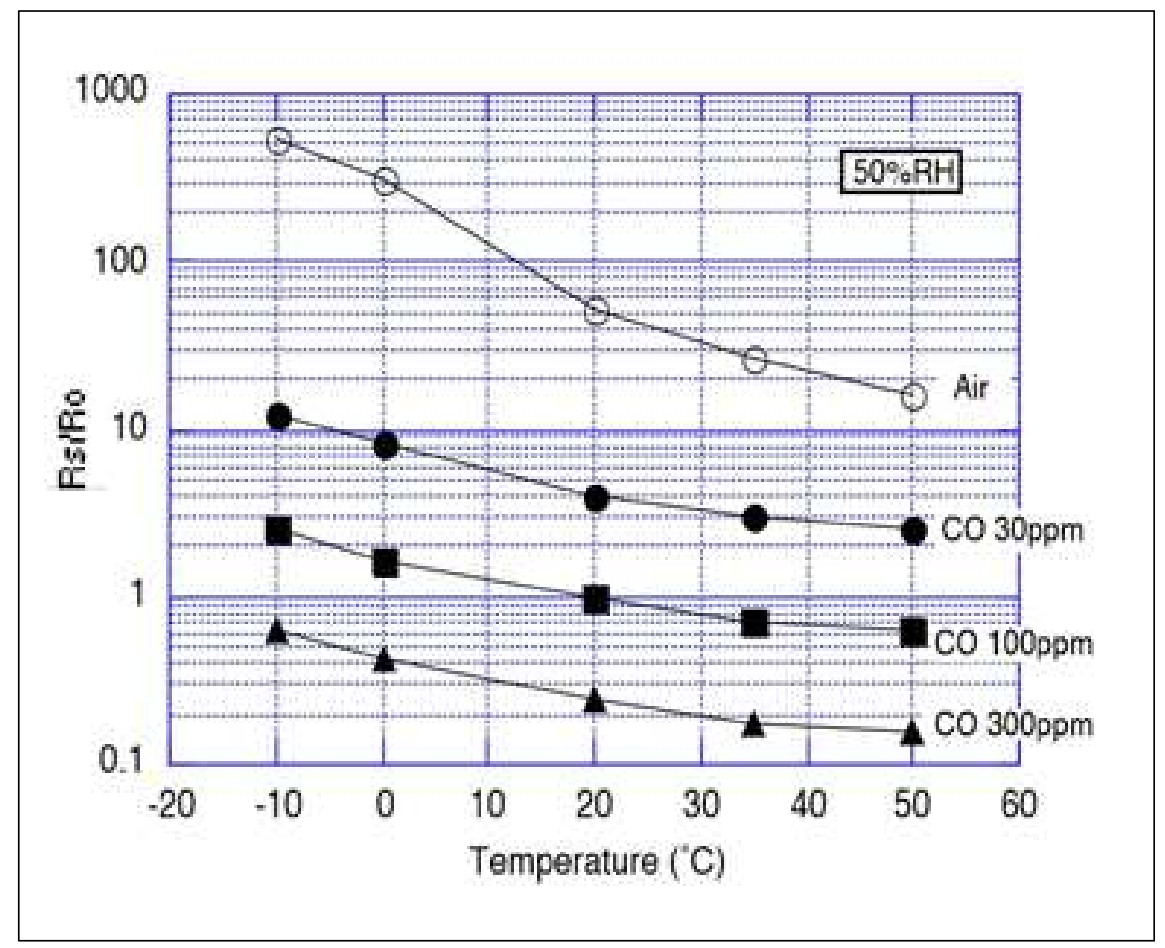

196 Fig.5 Influence of temperature and humidity on the TGS2442 sensor response curve.

IMR 1600 analyzer as shown in Figure 6.

201

202

203

204

205 

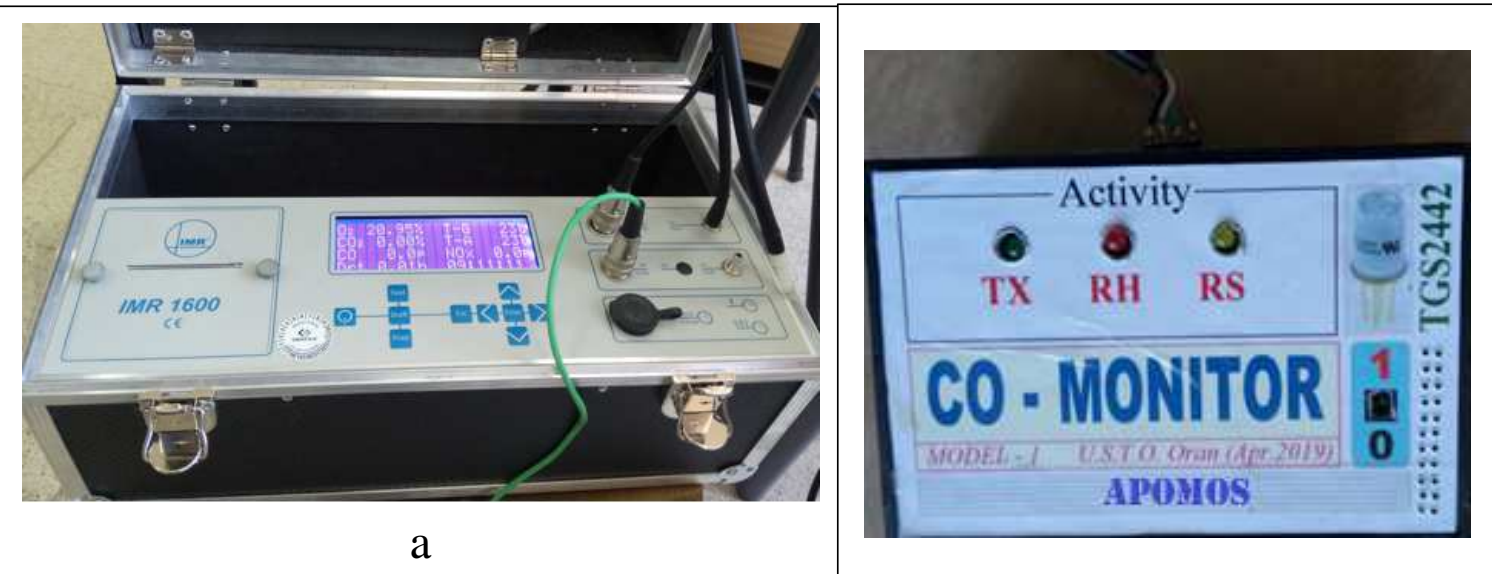

Fig.6 (a) GUNT IMR 1600 analyzer - (b) APOMOS system with TGS2442 carbon

212 monoxide sensor.

$213 \quad$ Source : Authors

214

215

The 2 measuring devices are placed in a containment chamber with a combustion

216 source. The measurements collected and presented in Figure 7 show a relative agreement of the values expressed in ppm.

218

219

220

221 


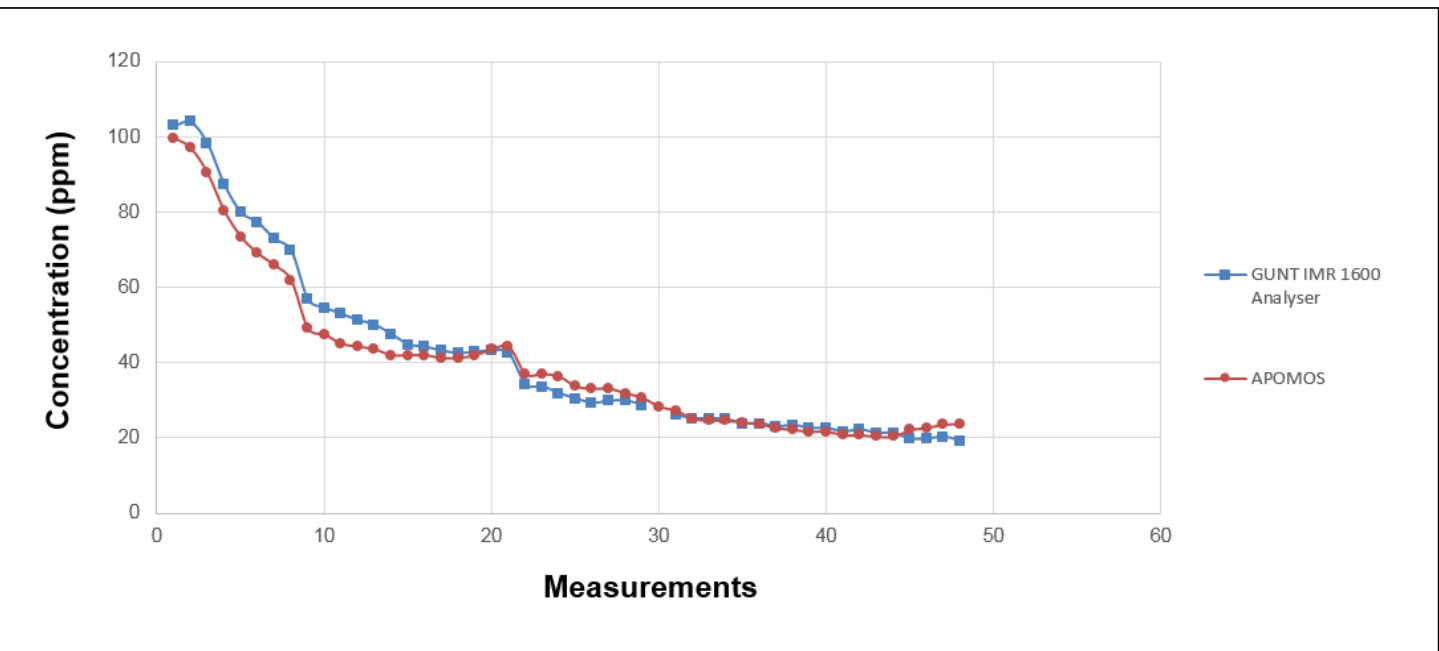

228

Fig.7 Comparison of the measurements expressed in ppm resulting from the GUNT

229 IMR 1600 analyzer and those resulting from the APOMOS system. 


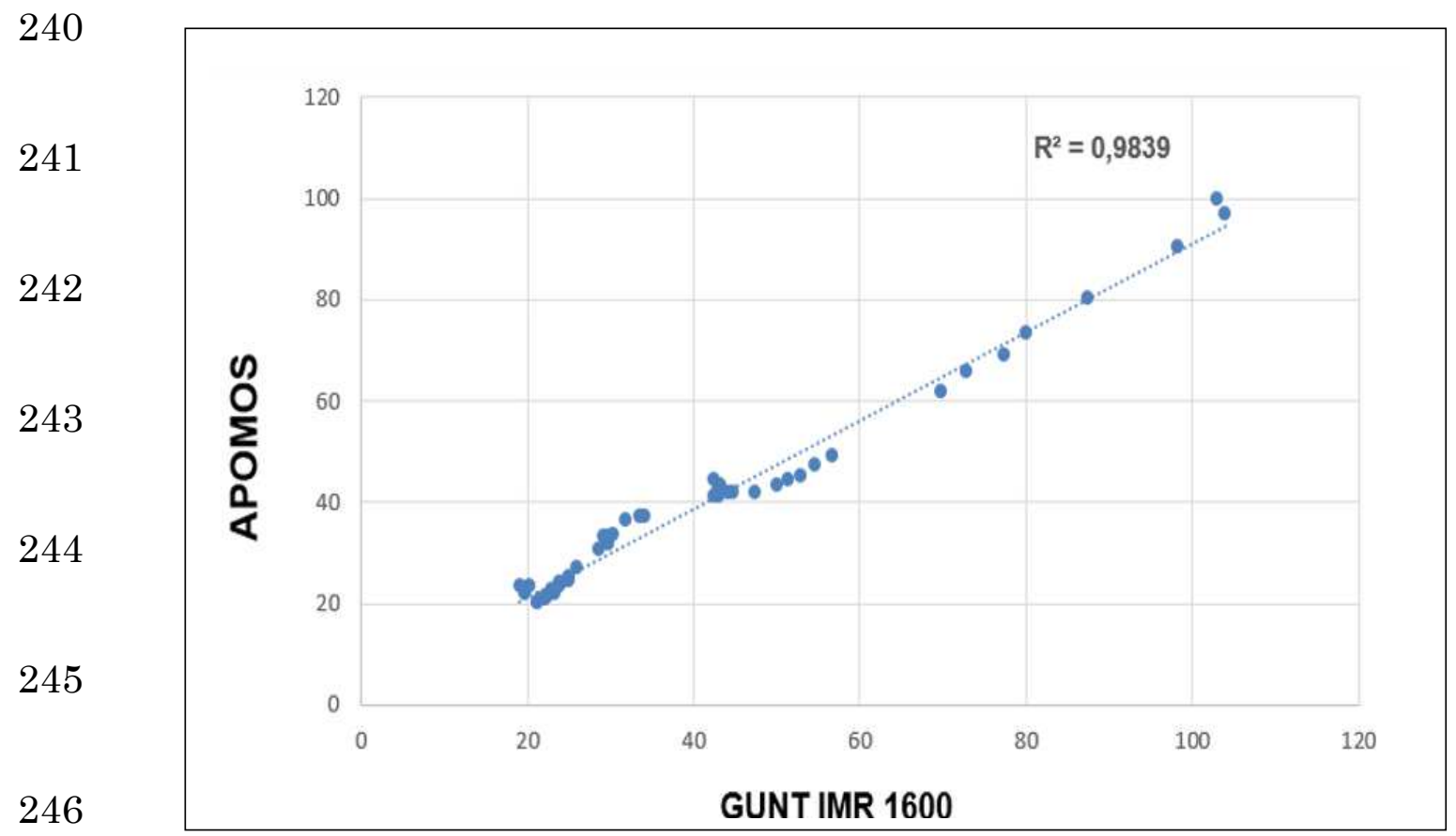

$247 \quad$ Fig.8 Comparison in point cloud of the measurements expressed in ppm resulting

248 from the GUNT IMR 1600 analyzer and those resulting from the APOMOS system.

$249 \quad$ Source : Authors

250

251 The APOMOS system is connected to the computer with a USB Serial TTL

252 converter allowing a USB connection to an RS232 link with a baud rate of $57600 \mathrm{bps}$.

253 The collected measurements are recorded in a database of SQLite type exploited by

254 an application developed with the Python language which provides strong support for

255 integration with other programming languages and other tools [19]. It allows us to

256 configure the measurement system, save the data, process it, display it as a graph, and 
258 in Figure 9, facilitates access to the different functionalities of the APOMOS system.

\begin{tabular}{|c|c|c|c|c|c|c|c|c|}
\hline \multirow{4}{*}{259} & \multicolumn{7}{|c|}{ DAPOHOS } & $-|ㅁ ㅣ| x \mid$ \\
\hline & \multirow{2}{*}{\multicolumn{7}{|c|}{ Monitoring Data ? }} & \\
\hline & & & & & & & & $?|x|$ \\
\hline & \multicolumn{7}{|c|}{ Stored data of $\mathrm{CO}$ concentration } & \\
\hline \multirow{3}{*}{260} & & Date & Time & Latitude & Longitude & $\mathrm{CO}(\mathrm{ppm})$ & A & \\
\hline & 1 & $03 / 06 / 2019$ & 11:00 & 35,703 & $-0,6382$ & 0,429198155 & & \\
\hline & 2 & $03 / 06 / 2019$ & 11:01 & 35,6991 & $-0,6305$ & 0,463056955 & & Reset \\
\hline \multirow{4}{*}{261} & 3 & $03 / 06 / 2019$ & 11:02 & 35,6941 & $-0,6462$ & 0,463056955 & & Dump \\
\hline & 4 & $03 / 06 / 2019$ & 11:03 & 35,6959 & $-0,6476$ & 0,498805231 & & \\
\hline & 5 & 03/06/2019 & 11:04 & 35,6964 & $-0,6482$ & 0,536506621 & & export \\
\hline & 6 & 03/06/2019 & 11:05 & 35,6969 & $-0,6478$ & 0,536506621 & & Chart \\
\hline \multirow{4}{*}{262} & 7 & 03/06/2019 & 11:06 & 35,6973 & $-0,6472$ & 0,66197771 & & \\
\hline & 8 & $03 / 06 / 2019$ & 11:07 & 35,6978 & $-0,6465$ & 0,708143701 & & \\
\hline & 9 & $03 / 06 / 2019$ & 11:08 & 35,6983 & $-0,6462$ & 0,618027252 & & \\
\hline & 10 & |03/06/2019 & 11:09 & 35,6988 & $-0,6467$ & 0,66197771 & & \\
\hline \multirow{4}{*}{263} & 11 & $03 / 06 / 2019$ & 11:10 & 35,6992 & $-0,6473$ & 0,618027252 & & \\
\hline & 12 & 03/06/2019 & 11:11 & 35,6998 & $-0,648$ & 0,576225555 & & \\
\hline & 13 & $03 / 06 / 2019$ & 11:12 & 35,7003 & $-0,6479$ & 0,498805231 & & \\
\hline & 14 & $03 / 06 / 2019$ & 11:13 & 35,7008 & $-0,6478$ & 0,498805231 & & \\
\hline \multirow{2}{*}{264} & 15 & $03 / 06 / 2019$ & 11:14 & 35,7014 & $-0,6474$ & 0,536506621 & -1 & \\
\hline & & & & OK & & & & \\
\hline
\end{tabular}

$265 \quad$ Fig.9 APOMOS system interface.

$266 \quad$ Source : Authors

267 system to form a mobile version. Thus, measurements of $\mathrm{CO}$ concentration can be referenced in space and time during itinerant campaigns for the assessment of air

271 quality in the city of Oran. 


\section{Results and discussion}

The systems commonly used for monitoring air pollution consist of stations with

large fixed sensors that continuously measure air pollutants. However, the

establishment of these stations is limited by factors such as the prohibitive costs of

control devices and sensors, the large size of the sensors used, the high power

consumption and other technical complexities [20]

280

The public authorities have equipped the city of Oran with a network of 4

281 conventional air quality measurement stations. However, this measurement network is

282 not operational until now.

283 Data on concentrations of air pollutants in Oran were collected during some

284 academic research such as Zenata [21].

285 The APOMOS system with its 2 versions, one fixed and the other embedded, fills

286 a considerable gap in air quality data in Oran.

287 The fixed version of the APOMOS system has been placed at the center of the city

288 of Oran which has a dense urban traffic. The profile of carbon monoxide concentrations

289 for a working day is shown in Figure 10. Concentration peaks correspond to the

290 morning peak hour, which can reach 1717 vehicles / hour [22]. Another peak of lower 
291 intensity concentration is observed at evening peak hour.

292

293

294

295

296

\section{$\mathrm{CO}(\mathrm{ppm})$ at the center of Oran}

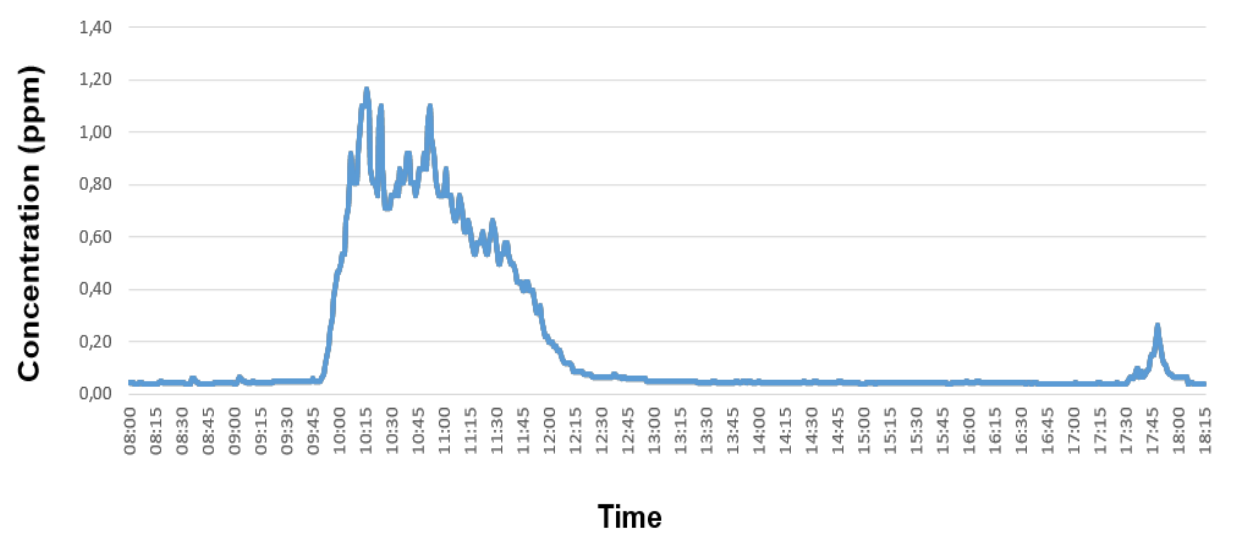

Fig.10 Profile of carbon monoxide concentrations in ppm for a working day

collected in June 2019 by the fixed version of the APOMOS system in downtown Oran.

300

Source : Authors

301

302

The carbon monoxide concentrations recorded in Oran are of the same order of

303

magnitude as the concentrations measured by the air quality monitoring station in the

304

Bab-el-oued district in downtown Algiers as shown Figure 11.

305

306

307 


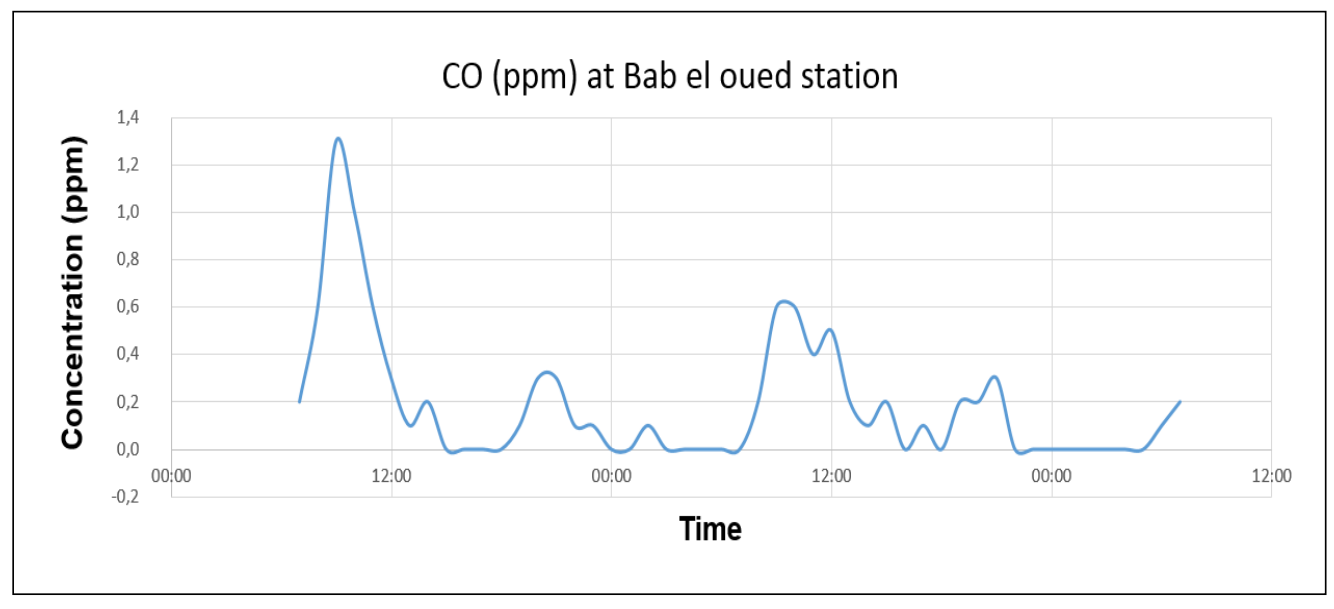

312

314 in Algiers in August 2006.

315 Source: The National Observatory for the Environment and Sustainable

316 Development.

The concentrations recorded in Oran oscillate between 0.1 and $1.2 \mathrm{ppm}$. This is also the case with the Larbi Ben M'hidi street, which is considered to be the backbone of downtown Oran [23], of which Figure 12A shows the proportions of the maximum concentration recorded in downtown. Despite its congestion, this street is quite wide and airy by one of the prevailing winds in Oran west-southwest [24]. This explains relatively low carbon monoxide concentrations. 
326 Boulevard which includes an emblematic place in Oran commonly known as Tahtaha.

327 It is a Boulevard with intense commercial activity. In addition, the measurements with

328 the mobile version of the APOMOS system coincided with the eve of the Muslim

329 festival of Aid El Fitr which knows a large influx of citizens for purchases related to

330 this celebration.

331

332

333

334

335

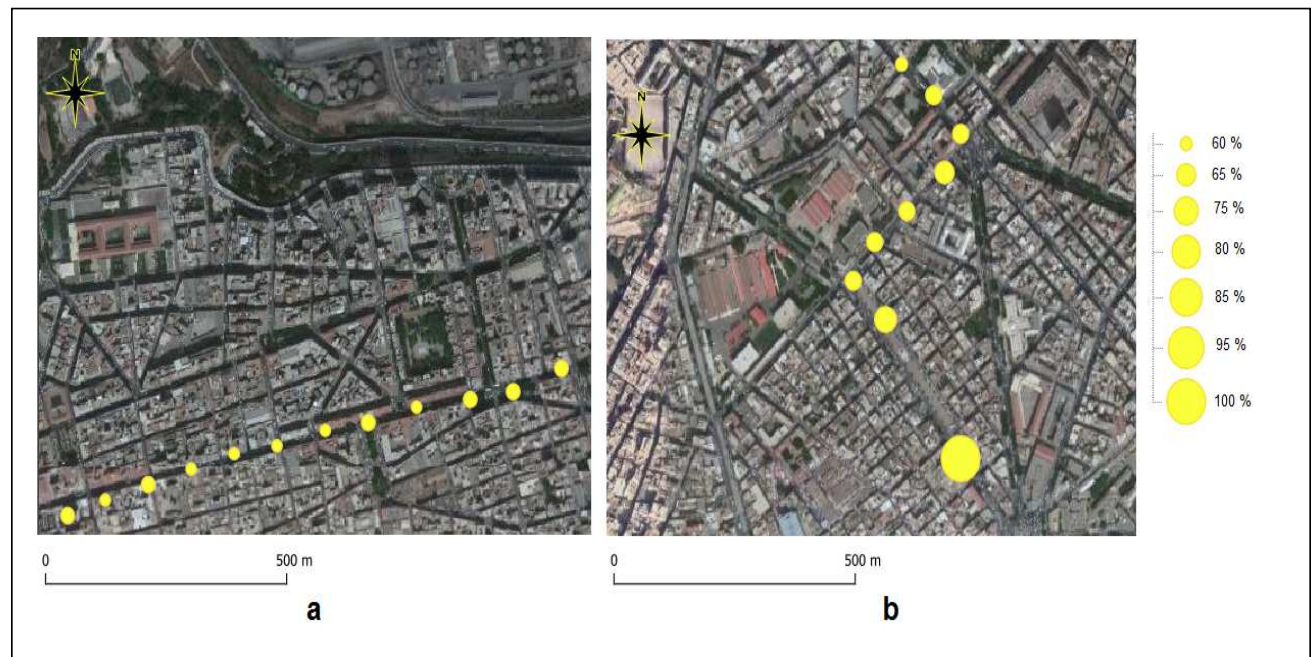

Fig.12 (a) Percentages of maximum concentration acquired on June 03rd, 2019 by

337 the mobile version of the APOMOS system for measurement points on Rue Larbi Ben

338 H'hidi in downtown Oran.

(b) Percentages of maximum concentration acquired on June 03rd,

3402019 by the mobile version of the APOMOS system for the measurement points of the

341 Independence Boulevard called Tahtaha in downtown Oran. 
344 Admittedly, the concentrations recorded are far from the level set by the World

345 Health Organization [25] guidelines as the main streets of the city are large and subject

346 to prevailing winds. However, these concentrations could increase significantly during

347 special weather events that prevent winds from circulating. This situation will be even

348 more problematic in the narrow downtown streets, which are lined with tall buildings

349 forming canyon streets. Hence the interest of constant and widely distributed

350 surveillance in space.

\section{Conclusions}

354 because the monitoring of air pollution is a costly policy, which requires sufficient and

355 sustainable financial means. In Algeria, despite the investments made to acquire these

356 surveillance networks, they are no longer operational.

357 The purpose of this work is the development of an affordable air quality

358 measurement system in several aspects: the cost, the realization and the exploitation. 
360 It was purchased less than 7 dollars, its cost and that of the other components, enables

361 the realization of several replicas of APOMOS system. In addition, the use of open

362 source and free programming tools helps to control development costs. The small

363 dimensions of the designed system make it portable and easy to operate.

364 Thus, the availability of portable personal analyzers for monitoring the air quality

365 at low cost and low consumption can help significantly denser monitoring networks in

366 urban pollution [27]. These new technologies with production at the lowest cost allow

367 global and fast distribution [28].

368 The APOMOS system has been validated and tested in the city of Oran for carbon

369 monoxide only but its scalability is ensured by the design of the electronic assembly.

370 The APOMOS system can then easily accommodate other sensors to measure the

371 concentrations of other air pollutants.

372 The replication of APOMOS system will make it possible to carry out continuous

373 measurements of air pollution spread over large geographic areas, especially in urban

374 areas, thus helping to protect people from exposure to poor air quality. 


\section{$\underline{\text { Declarations }}$}

\section{$378 \quad$ Availability of data and materials}

379 All data generated or analyzed during this study can be obtained from the

380 corresponding author.

\section{Competing interests}

382 The authors declare they have no competing interests.

\section{Funding}

384 The authors confirm that no funding was received to carry out this study.

385 Authors' contributions

386 All the authors have contributed to the structure, content, and writing of the

387 paper. All authors read and approved the final manuscript.

\section{Acknowledgements}

389 The authors wish to thank the National Polytechnic School of Oran - Maurice Audin,

390 for providing the analyzer which enabled the validation of the APOMOS system.

\section{References}

393 [1] Abderrahim H, Chellali MR, Hamou A. Forecasting PM 10 in Algiers: 
394 Efficacy of multilayer perceptron networks. Environmental Science and Pollution

$395 \quad$ Research. 2016 Jan 1;23(2):1634-41.

396 [2] .Talbi A, Kerchich Y, Kerbachi R, Boughedaoui M. Assessment of annual 397 air pollution levels with PM1, PM2. 5, PM10 and associated heavy metals in Algiers, 398 Algeria. Environmental Pollution. 2018 Jan 1;232:252-63.

399 [3] Trache SM. Mobilités résidentielles et périurbanisation dans l'agglomération 400 oranaise. Doctoral dissertation, Thèse de doctorat d'État, Oran University, 401 Algeria.2010.

402 [4] Maachou HM. Agriculture et paysage des espaces périurbains algériens. 403 Projets de paysage. 2012;7.

404 [5] Maachou HM, Otmane T. L'agriculture périurbaine à Oran (Algérie): 405 diversification et stratégies d'adaptation. Cahiers Agricultures. 2016 Mar $406 \quad 1 ; 25(2): 25002$.

407 [6] Rahal F, Hadjou Z, Blond N, Aguejdad R. Croissance urbaine, mobilité et 408 émissions de polluants atmosphériques dans la région d'Oran, Algérie. Cybergeo: 409 European Journal of Geography. 2018 Apr 18.

410 [7] Snyder EG, Watkins TH, Solomon PA, Thoma ED, Williams RW, Hagler 
411 GS, Shelow D, Hindin DA, Kilaru VJ, Preuss PW. The changing paradigm of air

412 pollution monitoring.

413 [8] Morawska L, Thai PK, Liu X, Asumadu-Sakyi A, Ayoko G, Bartonova A,

414 Bedini A, Chai F, Christensen B, Dunbabin M, Gao J. Applications of low-cost sensing

415 technologies for air quality monitoring and exposure assessment: How far have they

416 gone?. Environment international. 2018 Jul 1;116:286-99.

417 [9] Maag B, Zhou Z, Thiele L. A survey on sensor calibration in air pollution

418 monitoring deployments. IEEE Internet of Things Journal. 2018 Jul 6;5(6):4857-70.

419 [10] Rai AC, Kumar P, Pilla F, Skouloudis AN, Di Sabatino S, Ratti C, Yasar A,

420 Rickerby D. End-user perspective of low-cost sensors for outdoor air pollution

421 monitoring. Science of The Total Environment. 2017 Dec 31;607:691-705.

422 [11] Baron R, Saffell J. Amperometric gas sensors as a low cost emerging

423 technology platform for air quality monitoring applications: A review. ACS sensors.

4242017 Oct 26;2(11):1553-66.

425 [12] Yi WY, Lo KM, Mak T, Leung KS, Leung Y, Meng ML. A survey of 426 wireless sensor network based air pollution monitoring systems. Sensors. 2015

Dec;15(12):31392-427. 
429 Emissions. InEGU General Assembly Conference Abstracts 2018 Apr (Vol. 20, p.

430 7870).

431 [14] Liu C, Yin P, Chen R, Meng X, Wang L, Niu Y, Lin Z, Liu Y, Liu J, Qi J,

432 You J. Ambient carbon monoxide and cardiovascular mortality: a nationwide time-

433 series analysis in 272 cities in China. The Lancet Planetary Health. 2018 Jan 1;2(1):e12-

4348.

435 [15] Draut PG, Ionel R, Gontean AS, Ionel I. A new approach for carbon

436 monoxide measurement using virtual instrumentation. InProceedings of The 6th

437 WSEAS International Conference on Energy, Environment, Ecosystems and 438 Sustainable Development (EEESD’10) 2010 Oct (pp. 267-271).

439 [16] Salih ZQ, Al-Salihi AM, Rajab JM. Assessment of Troposphere Carbon

440 Monoxide Variability and Trend in Iraq Using Atmospheric Infrared Sounder During

441 2003-2016. Journal of Environmental Science and Technology. 2018;11:39-48.

442 [17] Liu JH, Chen YF, Lin TS, Lai DW, Wen TH, Sun CH, Juang JY, Jiang JA.

443 Developed urban air quality monitoring system based on wireless sensor networks.

444 In2011 Fifth International Conference on Sensing Technology 2011 Nov 28 (pp. 549- 
FIGARO. Signal Processing and Calibration Techniques for CO Detectors

447 Using TGS2442. 2001.

448 [19] Nofriansyah D, Freizello H. Python Application: Visual Approach of 449 Hopfield Discrete Method for Hiragana Images Recognition. Bulletin of Electrical 450 Engineering and Informatics. 2018 Dec 1;7(4):609-14.

451 [20] Shuma SN, Mwangi E, Karimi P. A Microcontroller Based Carbon Monoxide 452 Monitoring and Mapping System Using GPS Technology. International Journal of 453 Computer Applications. 2017;163(11).

454 [21] Zenata K., Etude de la pollution urbaine dans la wilaya d'Oran. Magister 455 dissertation, Oran University, Algeria. 2008

456 [22] Rahal F, Benharrats N, Rahal DD, Baba Hamed FZ. Influence du trafic 457 routier sur la pollution atmosphérique dans la ville d'Oran. Ghardaïa, Algeria 16-18 458 February 2009. 2008:153.

459 [23] Kadri Y, Kettaf F. Reconquête du quartier ancien Yaghmouracen d'Oran: 460 documents d'urbanisme et jeux d'acteurs en question. Cybergeo: European Journal of 461 Geography. 2018 Jun 15. 
[24] Benmedjahed M, Ghellai N, Benmansour A. Wind Potential Assessment of 463 Three Coastal Sites in Algeria: Calculation and Modeling of Wind Turbine Noise using

464 Matlab. International Journal of Computer Applications. 2012 Jan 1;56(2):20-5.

465 [25] World Health Organization. Environmental Health Criteria 213-Carbon 466 Monoxide. 1999. Available from URL: whqlibdoc. who. int. Diakses tanggal. 2009;19.

467 [26] Kumar A, Gurjar BR. Low-Cost Sensors for Air Quality Monitoring in 468 Developing Countries-A Critical View. Asian Journal of Water, Environment and 469 Pollution. 2019 Jan 1;16(2):65-70.

470 [27] Capezzuto L, Abbamonte L, De Vito S, Massera E, Formisano F, Fattoruso 471 G, Di Francia G, Buonanno A. A maker friendly mobile and social sensing approach to 472 urban air quality monitoring. InSENSORS, 2014 IEEE 2014 Nov 2 (pp. 12-16). IEEE. 473 [28] Trivedi KR, Mistry DP. Integration of GPS and GSM for the Weather 474 Monitoring System. Bulletin of Electrical Engineering and Informatics. 2012 Jun $475 \quad 23 ; 1(3): 209-12$. 
Figures

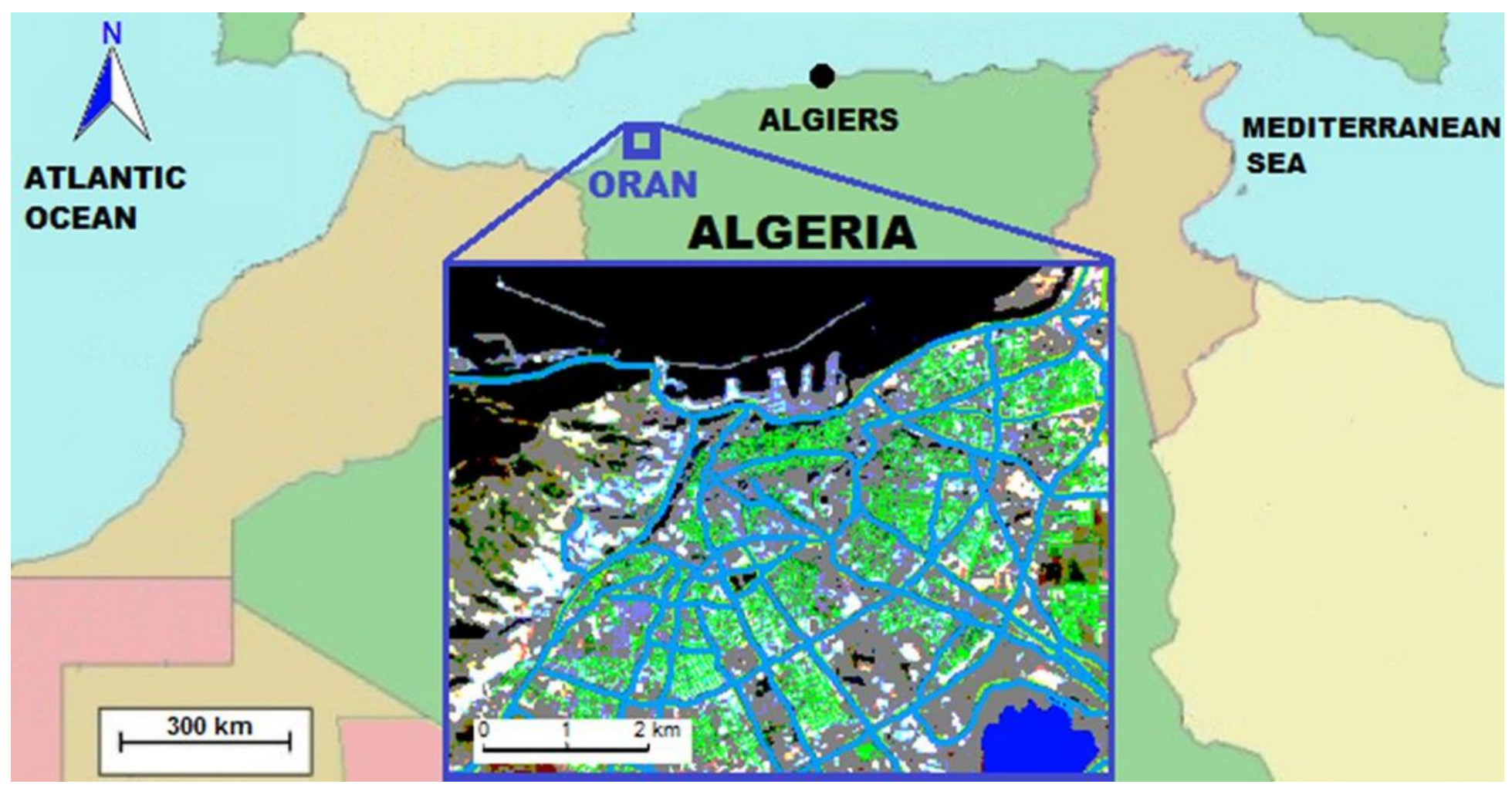

Figure 1

Geographic position of Oran city in Algeria. 


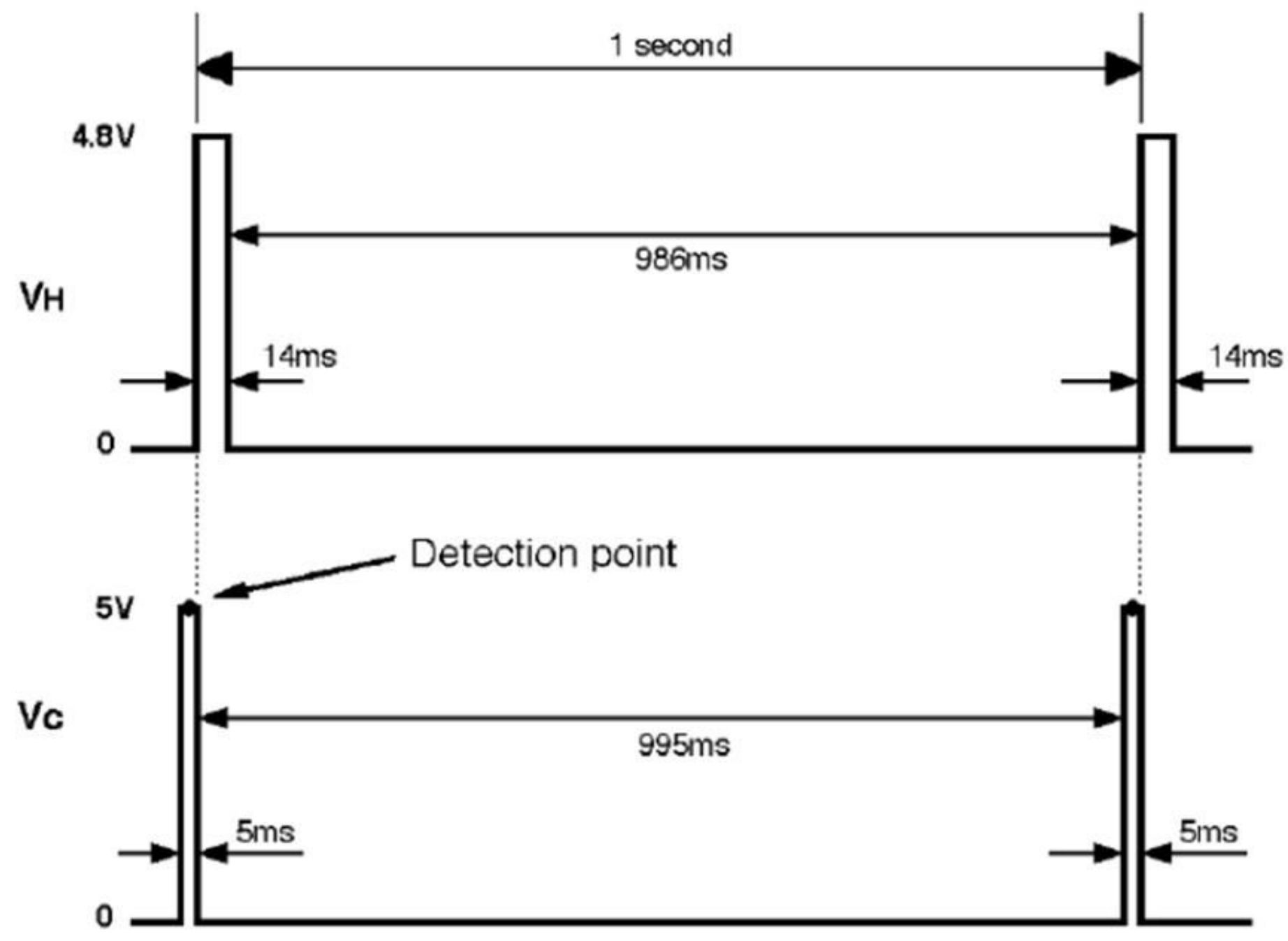

Figure 2

Circuit voltage and heating voltage cycles of TGS2442 Sensor. 


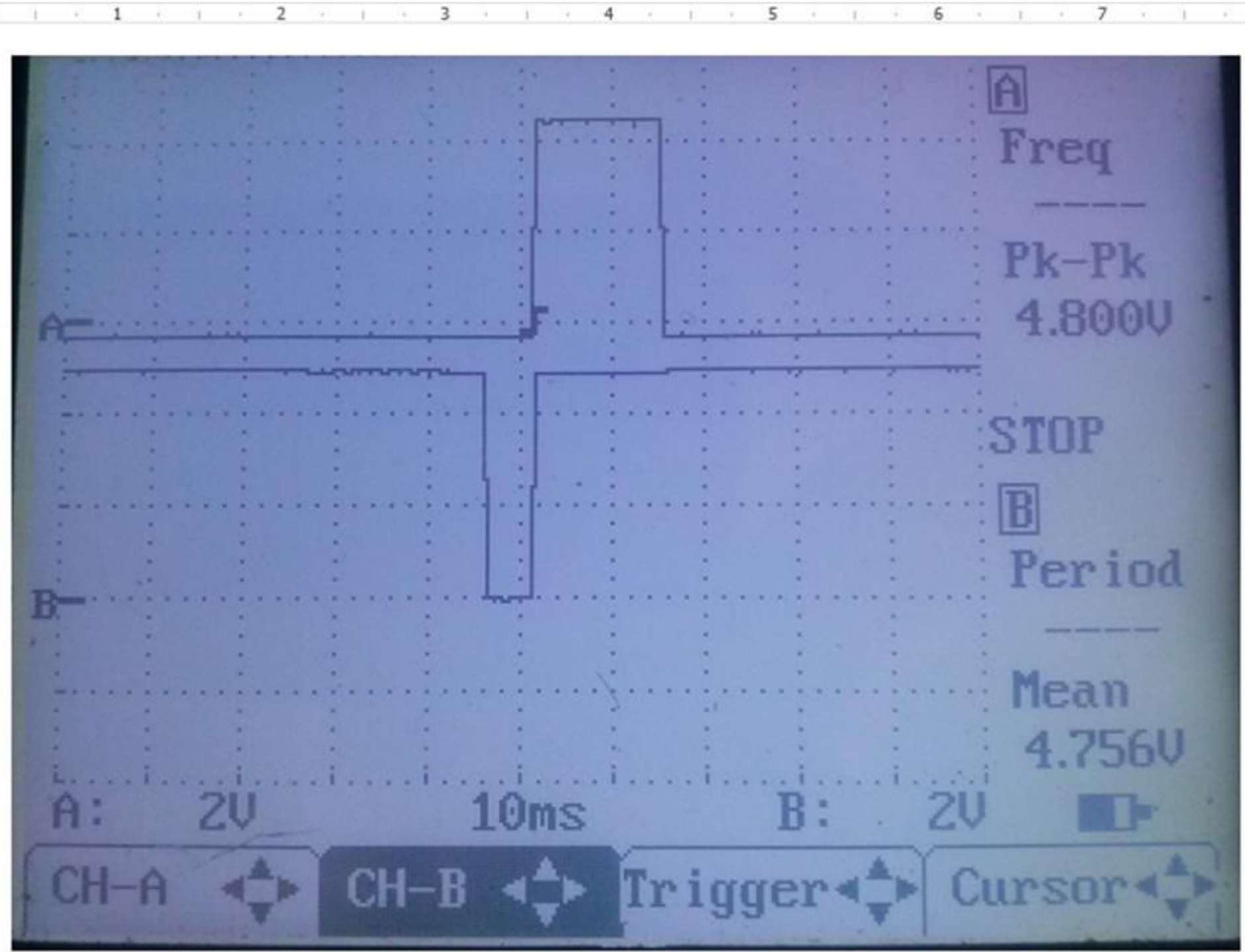

\section{Figure 3}

Double trace view of the outputs after 5 millisecond pulses followed by 14 millisecond pulses recorded by an oscilloscope. 


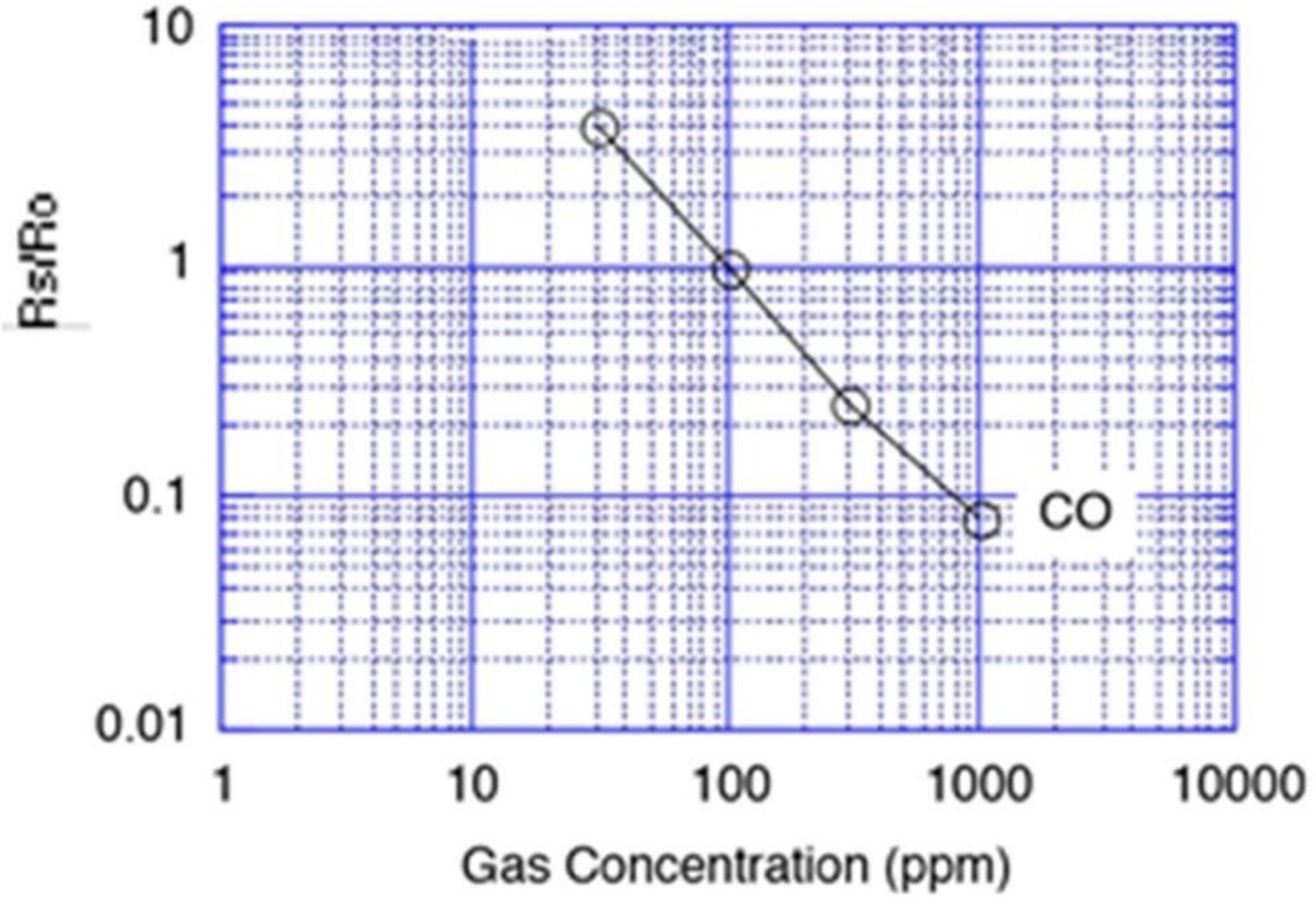

Figure 4

TGS2442 sensor response curves. 


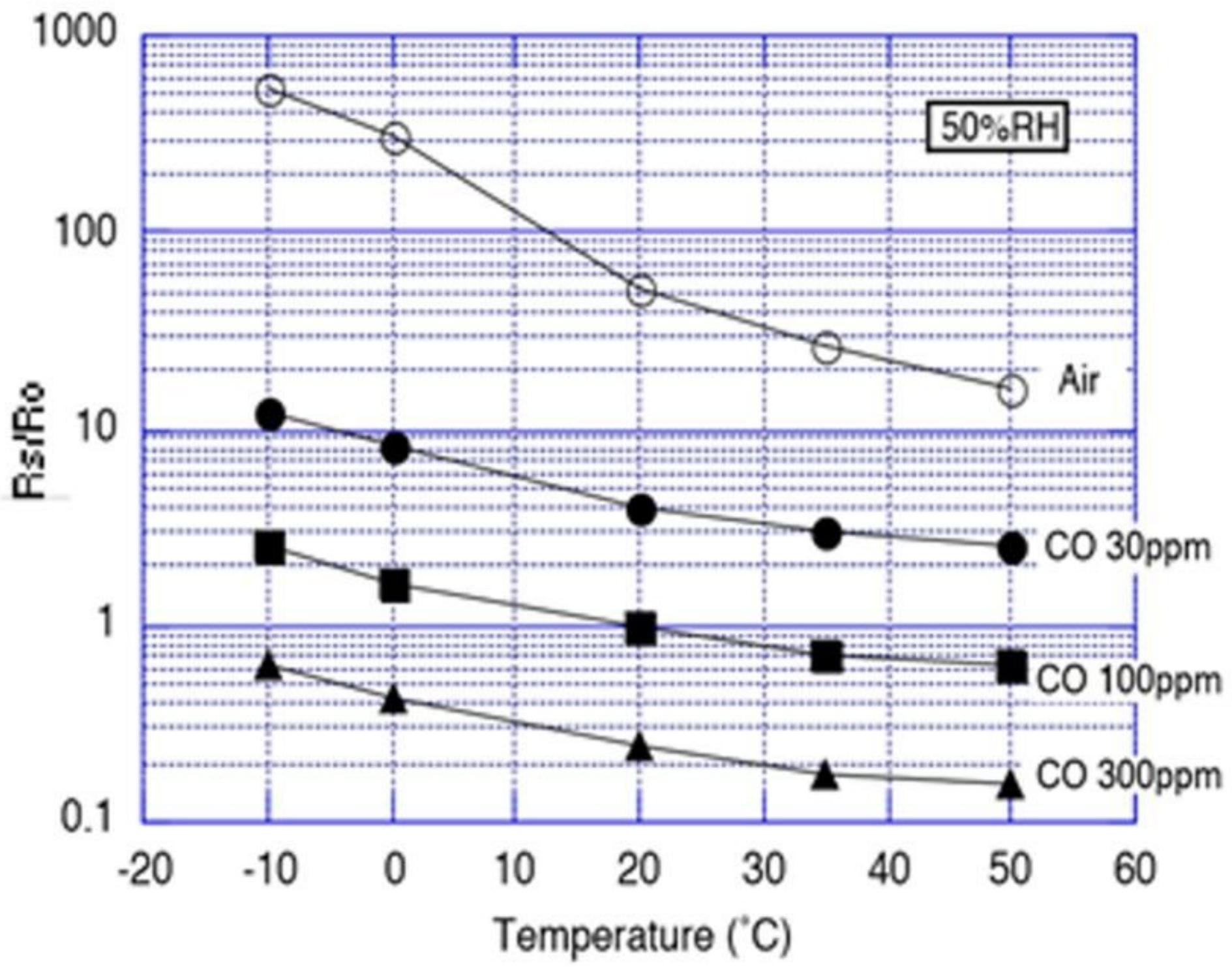

Figure 5

Influence of temperature and humidity on the TGS2442 sensor response curve. 


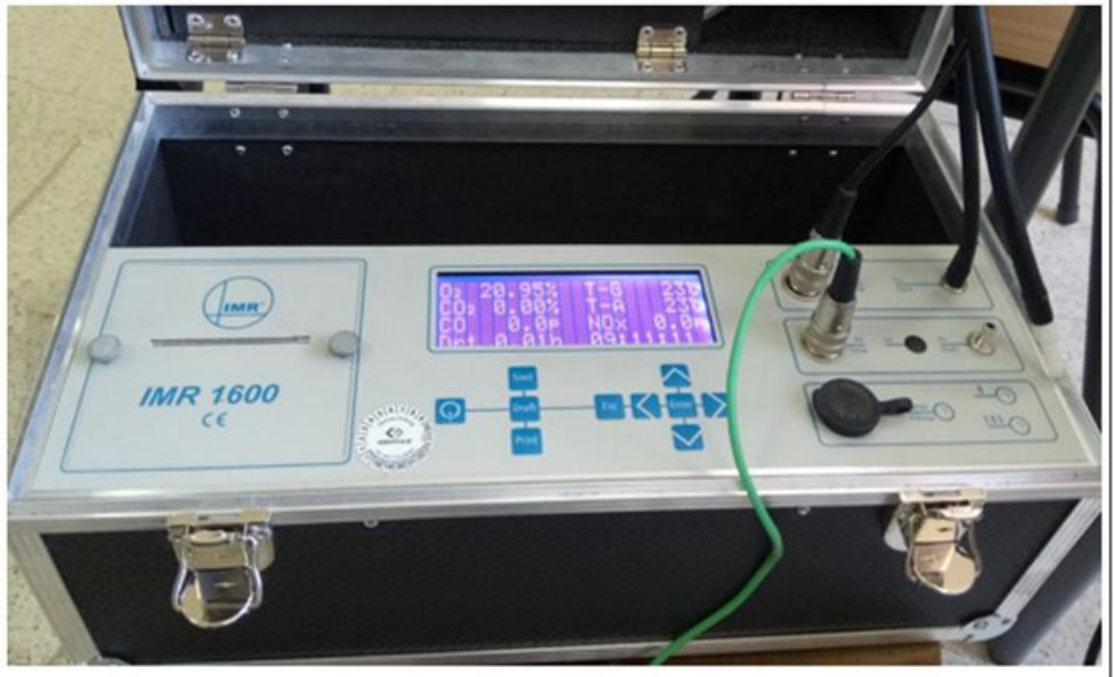

a

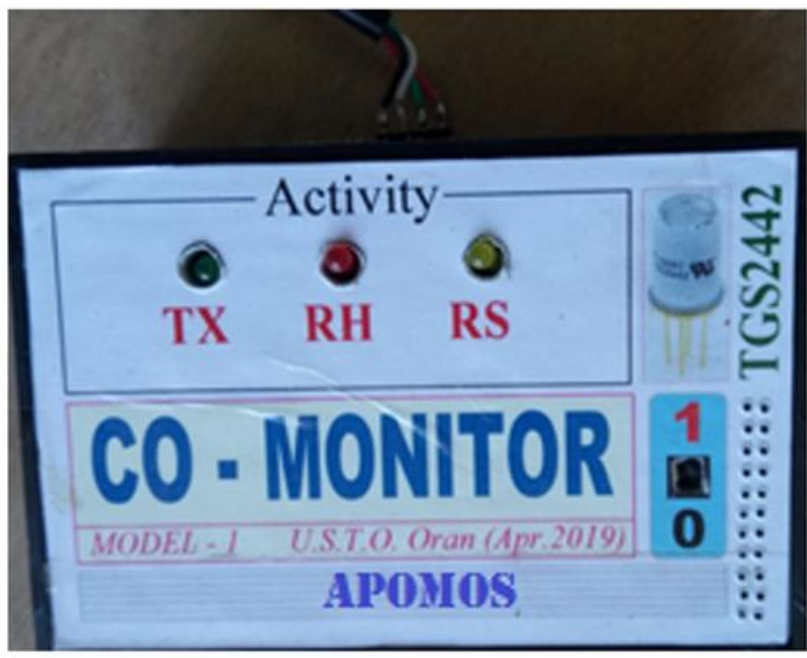

b

Figure 6

(a) GUNT IMR 1600 analyzer - (b) APOMOS system with TGS2442 carbon monoxide sensor.

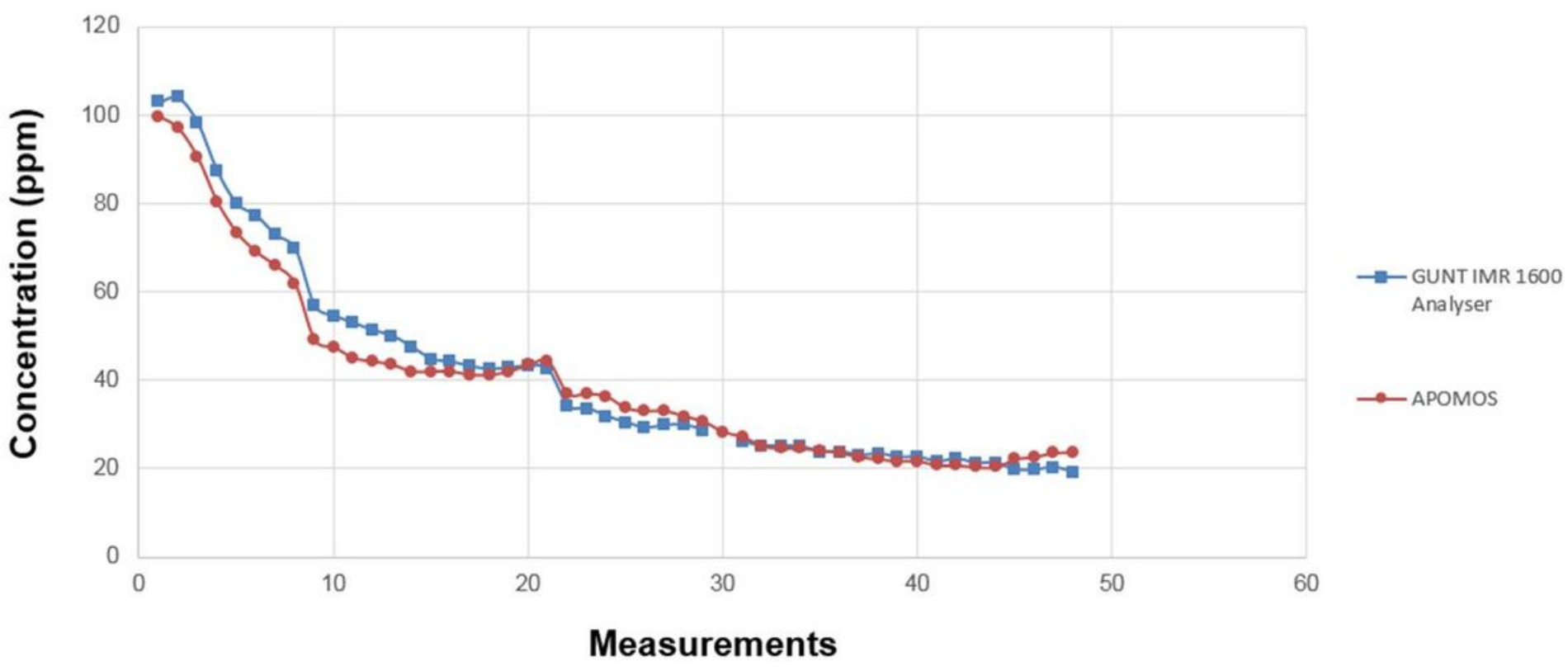

Figure 7

Comparison of the measurements expressed in ppm resulting from the GUNT229 IMR 1600 analyzer and those resulting from the APOMOS system. 


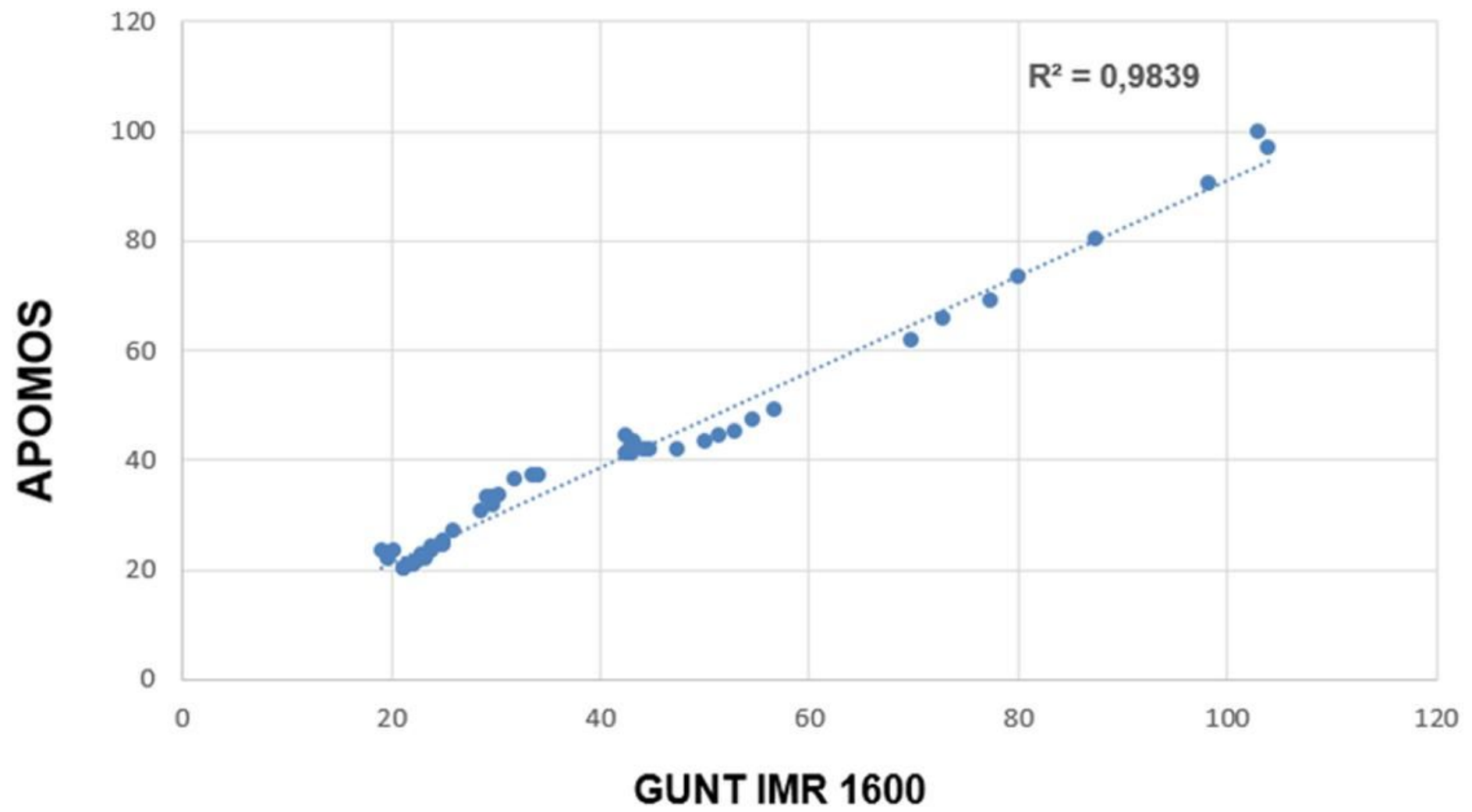

Figure 8

Comparison in point cloud of the measurements expressed in ppm resulting from the GUNT IMR 1600 analyzer and those resulting from the APOMOS system. 


\begin{tabular}{l}
\hline II: ApOMOS \\
Monitoring Data?
\end{tabular}

Stored data - CO

\section{Stored data of CO concentration}

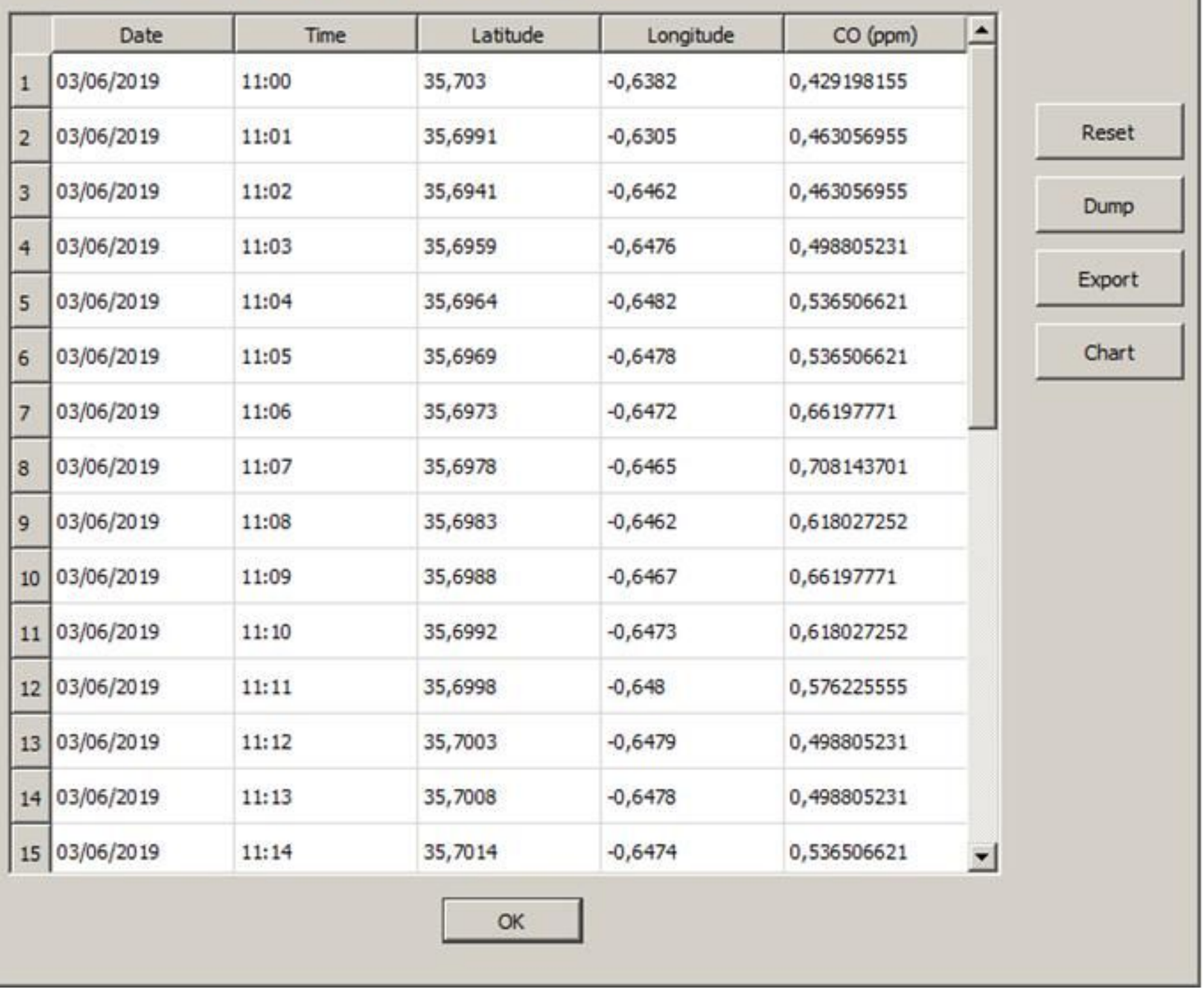

Figure 9

APOMOS system interface. 


\section{$\mathrm{CO}(\mathrm{ppm})$ at the center of Oran}

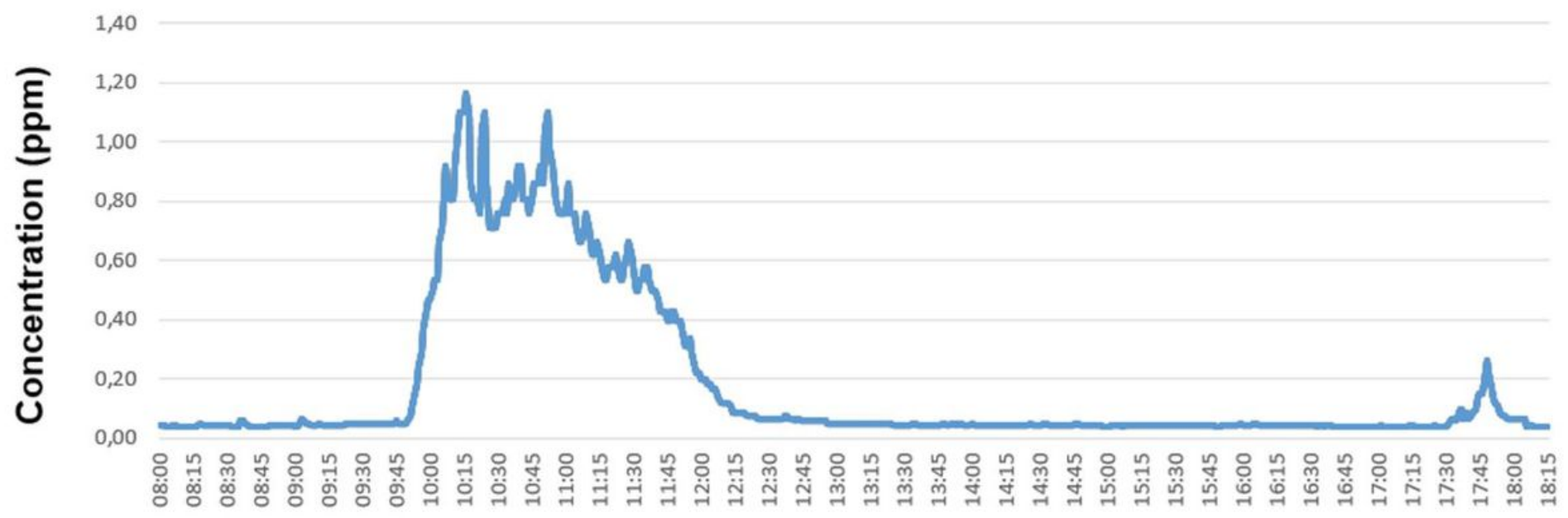

Time

Figure 10

Profile of carbon monoxide concentrations in ppm for a working day collected in June 2019 by the fixed version of the APOMOS system in downtown Oran.

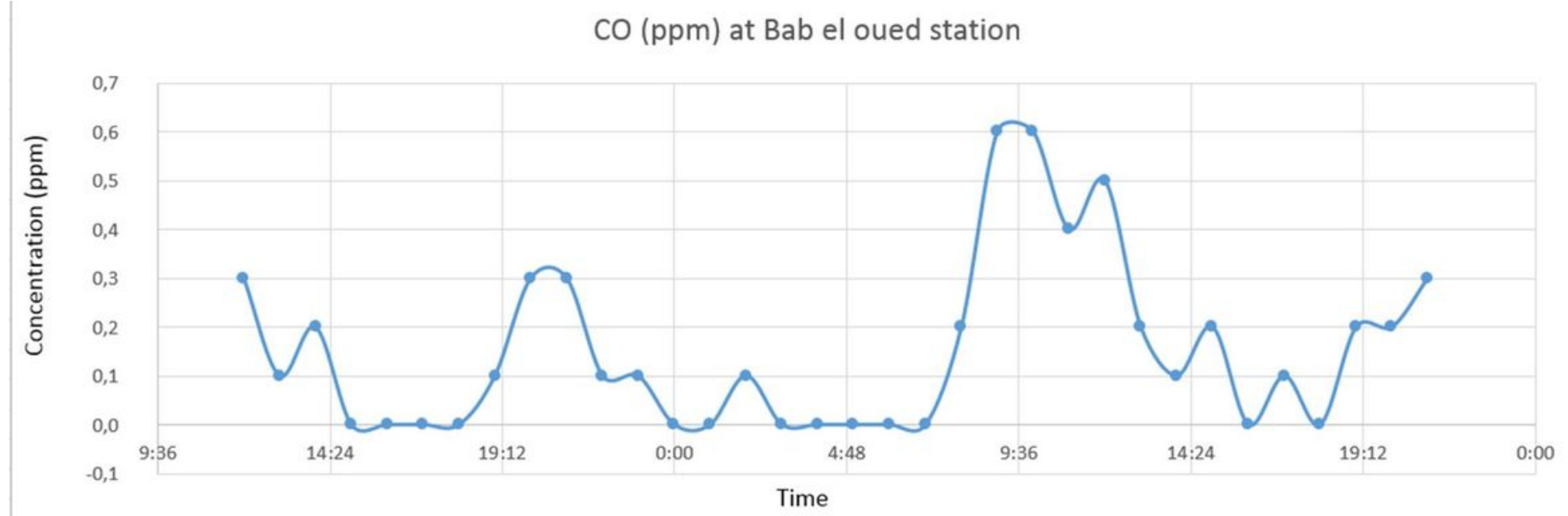

Figure 11

Concentrations of carbon monoxide recorded by the station of Bab-el-oued in Algiers in August 2006. 


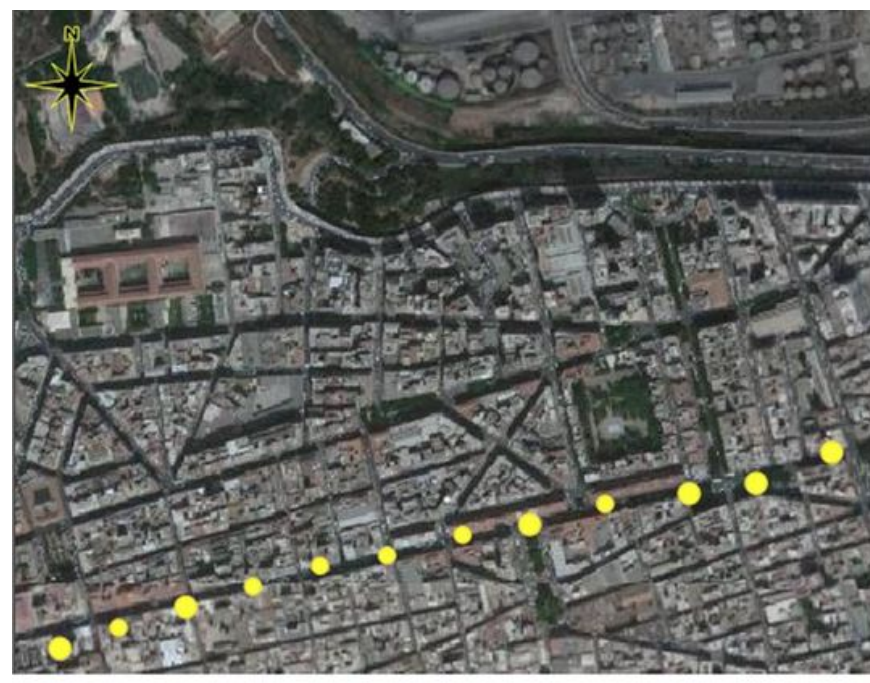

0 $500 \mathrm{~m}$

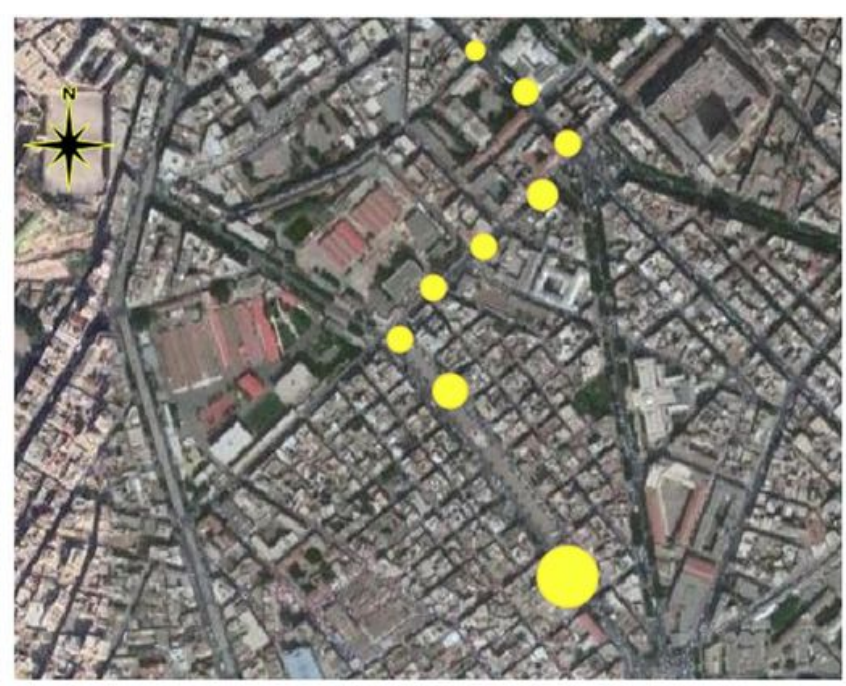

0

$500 \mathrm{~m}$
$60 \%$

$65 \%$

$75 \%$

$80 \%$

$85 \%$

$95 \%$

$100 \%$

Figure 12

(a) Percentages of maximum concentration acquired on June 03rd, 2019 by the mobile version of the APOMOS system for measurement points on Rue Larbi Ben H'hidi in downtown Oran. 